\title{
L forms of Staphylococcus aureus
}

\author{
By R. E. O. WILLIAMS \\ Wright-Fleming Institute of Microbiology, St Mary's Hospital \\ Medical School, London W. 2
}

(Received 23 May 1963)

SUMMARY

\begin{abstract}
All but four of twenty-five strains of Staphylococcus aureus exposed to concentrations of $60 \mu \mathrm{g}$. benzylpenicillin $/ \mathrm{ml}$. (or 100-500 $\mu \mathrm{g}$. methicillin/ ml. for penicillinase-producing strains) on nutrient agar media containing $3.5 \%(\mathrm{w} / \mathrm{v})$ sodium chloride and $10 \%(\mathrm{v} / \mathrm{v})$ horse serum, gave rise to typical $\mathrm{L}$ colonies. The $\mathrm{L}$ forms were subcultured on nutrient agar and in broth containing $3.5 \%$ sodium chloride and were found to be com. pletely resistant to the penicillins, cycloserine, ristocetin, vancomycin and cephalosporin, but to be sensitive to other antibiotics, often in slightly lower concentrations than the parent cocci. The $\mathrm{L}$ forms produced coagulase and, in two of three strains tested, were lysogenic although resistant to phage lysis. In studies of the transformation of staphylococci to $\mathrm{L}$ forms, it was noted that a variable but often very large proportion of the early L microcolonies failed to develop into typical colonies.
\end{abstract}

\section{INTRODUCTION}

During the last few years there has been considerable interest in the so-called ' $L$ forms' of various bacteria. Although the term $L$ form has been used with rather inadequate definition by many writers, there seems now to be general agreement that it is best used to refer to organisms, derived from typical bacteria, which can grow on suitable culture media but which lack an organized cell wall. This paper reports a study of organisms, derived from cultures of Staphylococcus aureus by exposure to penicillin in the presence of serum and a high concentration of sodium chloride, which are thought to lack the mucopeptide element of the normal cell wall. The production of $\mathbf{L}$ forms from staphylococci was described briefly by Dienes \& Sharp (1956) and in more detail by Schönfeld $(1959,1961)$, Marston $(1961 a, b)$ and Mattman, Tunstall \& Rossmoore (1961). The work reported here confirms many of the observations recorded previously and amplifies them with a study of the development of the $L$ colonies and of the sensitivity of the $L$ forms to a wide range of antibiotics; it also provides some additional evidence for the lack of an organized cell wall.

\section{METHODS}

Media. For most of the work described here, Difco Brain-Heart Infusion Broth or Agar was used, made up according to the makers' formula. For the standard 'L-form medium', there were added $3 \%(\mathrm{w} / \mathrm{v})$ sodium chloride (giving $3.5 \%$ total $\mathrm{NaCl}), 10 \%(\mathrm{v} / \mathrm{v})$ normal horse serum and $60 \mu \mathrm{g}$. (100 units) benzylpenicillin $/ \mathrm{ml}$. Agar media were poured in $20 \mathrm{ml}$. volumes in $9 \mathrm{~cm}$. plastic Petri dishes. After 
drying to remove surface water the plates were inoculated and incubated at $37^{\circ}$ enclosed in a polythene bag to prevent further drying.

Formation of staphylococcal $L$ forms. For the isolation of $\mathbf{L}$ colonies from staphylococci it was found best to inoculate the agar media with $0.5 \mathrm{ml}$. of a 10-times concentrated suspension of the staphylococci grown overnight in nutrient broth.

Subculture of $L$ colonies. For transfer of $\mathrm{L}$ colonies from one solid medium to another, blocks of agar with colonies on the surface were cut out and inverted on the new medium; they were pushed forward across the agar surface when growth appeared beneath them.

Growth was established in broth by the transfer of a block of agar carrying colonies to a screw-capped bottle containing 10-15 ml. of L-form broth. Latterly, following a suggestion from Dr W. J. Hijmans (Leiden, Netherlands) the agar block was disintegrated and a suspension of agar + colonies transferred to the broth.

Microscopic examination. The development of colonies on agar was observed by cutting out, at appropriate intervals, blocks of agar-carrying colonies, and inverting on them coverslips on which a drop of $1 \%(\mathrm{w} / \mathrm{v})$ ethanolic methylene blue had been placed; or alternatively on coverslips on which a mixture of $1 \%(\mathrm{w} / \mathrm{v})$ methylene blue and $1 \%(\mathrm{w} / \mathrm{v})$ azur II had been dried.

Strains. A great part of the work reported here was done with three strains of Staphylococcus aureus: PS 42E (NCTC 8418), PS 6 (NCTC 8403); 1444, a strain of phage type $3 \mathrm{~B} /+$ isolated in this laboratory. A number of confirmatory tests were made with other strains from the phage-propagating set (Blair \& Williams, 1961) and with strains isolated here.

\section{RESULTS}

\section{Characteristic $L$-form growth}

The term ' $\mathrm{L}$-form' is used here to refer to organisms growing on the special media to give the characteristic colonies described in previous work (e.g. Fig. 1 in Marston, $1961 \mathrm{a}$ ); these colonies are up to about $2 \mathrm{~mm}$. in diameter, are smooth, domed and have an entire edge. They are hard to the touch and microscopic examination shows that the centre part of the colony is formed deep in the agar. The colony spreads on the surface beyond the burrowing centre. The peripheral growth consists at first of spherical vesicles about 5-10 $\mu$ in diameter, which are later replaced by granular elements. The central part of the surface growth and the burrowing central growth seem to be made of small granular elements. Stained by methylene blue, the vesicles appear empty. With the methylene blue + azur stain some small granules were sometimes seen within the vesicles at their periphery. Prolonged incubation sometimes resulted in the formation of new burrowing foci at the periphery of the colony.

In broth culture, growth was in the form of microcolonies embedded in slimy material, shown by staining and enzyme digestion to consist largely of deoxyribonucleic acid. Microscopically the microcolonies consisted of clusters of vesicles and granular debris.

\section{Transformation to $L$ forms}

The typical sequence of events observed when 10-times concentrated suspensions of an overnight staphylococcal broth culture were spread on a plate of the L-form medium was as follows. After incubation for $24-48 \mathrm{hr}$. there were usually no macro- 
scopically visible colonies, but microscopic examination revealed numerous foci consisting of weakly staining discs or vesicles, each about 5-10 $\mu$ in diameter. After a further $48 \mathrm{hr}$. of incubation these foci were larger, consisting of more vesicles and a central granular area; differential focusing showed that some of the granules were in fact deep in the agar. After further incubation these foci grew and showed more extensive and often apparently multifocal penetration into the agar. Very often most of the foci subsequently degenerated and only a few formed typical $\mathrm{L}$ colonies. This description is based on several different experiments, three of which are recorded in Table 1 . In control experiments with the staphylococci inoculated on to media containing penicillin but only $0.5 \%$ sodium chloride, no similar foci or colonies developed.

Table 1. Formation of $L$ forms from staphylococci

\begin{tabular}{|c|c|c|c|}
\hline $\begin{array}{c}\text { Viable cocci* } \ldots \\
\text { inoculated }\end{array}$ & $\begin{array}{c}\text { Expt. } 1 \\
0.9 \times 10^{7} \\
\text { Type of L-growth }\end{array}$ & $\begin{array}{c}\text { Expt. } 2 \\
1 \cdot 3 \times 10^{7} \\
\text { nd number of colonies }\end{array}$ & $\begin{array}{c}\text { Expt. 3 } \\
10^{7} \\
\text { q.cm./culture plate }\end{array}$ \\
\hline Day 1 & $\begin{array}{l}\text { Vesicles, few with } \\
\text { granules; } 1.7 \times 10^{4}\end{array}$ & 0 & Vesicles; $1.8 \times 10^{4}$ \\
\hline Day 2 & $\begin{array}{l}\text { Vesicular with deep } \\
\text { granules; } 1 \cdot 1 \times 10^{4}\end{array}$ & $\begin{array}{l}\text { Vesicular with deep } \\
\text { granules; } 0.3 \times 10^{4}\end{array}$ & $\begin{array}{l}\text { Vesicular with deep } \\
\text { granules; } 2 \cdot 1 \times 10^{4}\end{array}$ \\
\hline Day 3 & n.e. & n.e. & $\begin{array}{r}\text { Vesicular with deep } \\
\text { granules; } 2.7 \times 10^{4}\end{array}$ \\
\hline Day 4 & n.e. & $\begin{array}{l}\text { Vesicular with deep } \\
\text { granules; } 0.7 \times 10^{4}\end{array}$ & n.e. \\
\hline Day 5 & n.e. & n.e. & n.e. \\
\hline Day 6 & $\begin{array}{l}\text { Typical L-form } \\
\text { colonies; } 0.5\end{array}$ & $\begin{array}{l}\text { Typical L-form } \\
\text { colonies; } 7 \times 10^{2}\end{array}$ & $\begin{array}{l}\text { Typical L-form } \\
\text { colonies; } 3\end{array}$ \\
\hline $\begin{array}{l}\text { No. L-form colonies/ } \\
\text { primary focus }\end{array}$ & $0.3 \times 10^{-4}$ & $1 \times 10^{-2}$ & $10^{-4}$ \\
\hline $\begin{array}{l}\text { No. L-form colonies/ } \\
\text { coccus* in inoculum }\end{array}$ & $6 \times 10^{-8}$ & $5.4 \times 10^{-5}$ & $3 \times 10^{-7}$ \\
\hline
\end{tabular}

The number of $\mathbf{L}$ colonies developing on the plates seemed variable, and many experiments were made to try to obtain more reproducible results, without success. Undoubtedly the degree of wetness of the agar is important, but the application of a piece of filter paper to the surface, found by Gooder \& Maxted (1961) to enhance the growth of $\mathbf{L}$ colonies of streptococci, had no effect. Great variability was seen even when the experiment was carried out with a semi-solid agar layer.

Effect of different penicillin concentrations. In several experiments the standard inoculum of staphylococci was applied to a series of plates of the L-form medium which differed only in penicillin concentration $(0 \cdot 6-60 \mu \mathrm{g} . / \mathrm{ml}$.). After a few days of incubation the $0 \cdot 6 \mu \mathrm{g}$. penicillin plates showed some colonies rather like those of staphylococci, but which were hard and partly embedded in the agar; they consisted of refractile bodies 1-2 $\mu$. in diameter. These colonies appear to be similar to those described by Prozorovskii (1959) and Marston (1961 $a$ ) as developing on media with a low penicillin concentration. Examination of the $0.6 \mu \mathrm{g}$. plates daily after inoculation showed that, in contrast to the usual sequence of events on $60 \mu \mathrm{g}$. 
plates, the first foci to be visible were granules burrowing into the agar; vesicles were rarely seen. In only one of the five completed experiments (Table 2) were typical $\mathrm{L}$ colonies seen on $\mathbf{0} \cdot 6 \mu \mathrm{g} . / \mathrm{ml}$. plates. With all penicillin concentrations from $3 \mu \mathrm{g} . / \mathrm{ml}$. upwards typical $\mathrm{L}$ colonies developed.

\section{Table 2. Change of staphylococci to L forms on media with differing} penicillin concentrations

\begin{tabular}{|c|c|c|c|c|c|c|}
\hline $\begin{array}{l}\text { Concen- } \\
\text { tration } \\
\text { of } \\
\text { penicillin }\end{array}$ & $\begin{array}{c}\text { Day of } \\
\text { exami- }\end{array}$ & Expt. 1 & $\begin{array}{c}\text { Expt. } 2 \\
\text { No. }\end{array}$ & $\begin{array}{l}\text { Expt. } 3 \\
\text { and form }\end{array}$ & $\begin{array}{l}\text { Expt. } 4 \\
\text { of colonies }\end{array}$ & Expt. 5 \\
\hline \multirow[t]{2}{*}{$0 \cdot 6$} & $1-3$ & $\begin{array}{l}3 \cdot 7 \times 10^{4} \\
\text { S }+ \text { D: } 89 \% \\
D: 11 \%\end{array}$ & $\begin{array}{l}17 \times 10^{4} \\
\text { All D }\end{array}$ & $\begin{array}{l}1.9 \times 10^{4} \\
\text { All } \mathrm{D}\end{array}$ & $\begin{array}{l}3.9 \times 10^{4} \\
\text { D: } 25 \% \\
\text { S+D: }: 41 \% \\
\text { S: } 34 \%\end{array}$ & $\begin{array}{l}2 \cdot 7 \times 10^{4} \\
\mathbf{R B}: 100 \%\end{array}$ \\
\hline & $4-6$ & $\begin{array}{l}0 \cdot 8 \times 10^{4} \\
\text { All RB }\end{array}$ & $\begin{array}{l}16 \times 10^{4} \\
\text { All RB }\end{array}$ & $\begin{array}{l}4 \times 10^{2} \\
\text { All } \mathrm{RB}\end{array}$ & $\begin{array}{l}1.5 \times 10^{4} \\
\text { All } \mathrm{RB}\end{array}$ & $\begin{array}{l}\text { Semi-confluent } \\
\mathbf{L} \text { col. }\end{array}$ \\
\hline \multirow[t]{2}{*}{60} & $1-3$ & $\begin{array}{l}2.8 \times 10^{4} \\
\text { All S }\end{array}$ & $\begin{array}{l}6 \times 10^{2} \\
\text { All } S+D\end{array}$ & $\begin{array}{l}9 \cdot 1 \times 10^{4} \\
\text { All } \mathrm{D}\end{array}$ & $\begin{array}{l}5 \times 10^{4} \\
\text { All } \mathrm{S}\end{array}$ & $\begin{array}{l}1 \cdot 1 \times 10^{4} \\
\text { All S }\end{array}$ \\
\hline & $4-6$ & $\begin{array}{l}\text { Semi-confluent } \\
\text { All L col. }\end{array}$ & $\begin{array}{l}10^{2} \\
\text { All } L \text { col. }\end{array}$ & $\begin{array}{l}1 \cdot 7 \times 10^{2} \\
\text { All } \mathrm{L} \mathrm{col} \text {. }\end{array}$ & $\begin{array}{l}3.5 \times 10^{4} \\
\text { L. col } 14 \% \\
\text { S+D: } 20 \% \\
\text { Degenerate: } 66 \%\end{array}$ & $\begin{array}{l}0 \cdot 4 \times 10^{4} \\
\text { All L col. }\end{array}$ \\
\hline
\end{tabular}

Little further study has yet been made of the colonies which developed on the $0 \cdot 6 \mu \mathrm{g}$. plates, partly because of the difficulty of freeing them from staphylococci, but it seems that it is possible to carry them in subculture indefinitely and that they revert quantitatively to staphylococci in the absence of penicillin.

Proportion of staphylococcal strains transformed to $L$ phase. Twenty-five different staphylococcal strains have been tested for the formation of $\mathbf{L}$ forms. Eighteen of the strains, including the three (PS 42E, PS 6 and 1444) on which most of the detailed tests were done were penicillin-sensitive and seven were penicillin-resistant; the latter were tested on agar-containing methicillin. All but two of the eighteen penicillin-sensitive and two of the seven resistant strains yielded $L$ colonies, and many gave a profuse growth. The penicillin-resistant strains tested on methicillin agar tended to give fewer colonies than the sensitive strains tested on agar containing benzylpenicillin; a similar difference was found when sensitive strains were tested on methicillin agar.

\section{Subculture of $L$ forms}

In most cases subculture of colonies by the block transfer method was successful, although the proportion of colonies which yielded growth was often small on the first subculture of newly transformed strains. Established strains gave a profuse growth of secondary colonies after overnight incubation.

Considerable difficulty was experienced in establishing cultures in broth by inoculation with agar blocks containing colonies, though three broth lines were initiated by this method. The use of disintegrated agar blocks, adopted recently, 
appears more promising but still has not been consistently successful. Once established, the broth cultures were readily subcultured.

Growth in absence of penicillin. The nutrient agar and the broth cultures were carried for many subcultures in the L-form medium without penicillin. For example, a broth culture of the $L$ form of staphylococcus PS 42E was established in July 1961, and after three subcultures in penicillin-containing media was transferred successively 23 times in penicillin-free media during the next 7 months. Subculture to appropriate media at frequent intervals yielded, except on the one occasion noted below, only typical L colonies and no staphylococci. Similar series of subcultures of the other two strains were made in the absence of penicillin. Agar-plate subcultures were also kept growing over the same period although, because the plates became contaminated from time to time, it was not possible to complete the entire series exclusively on penicillin-free media. A total of 16-20 subcultures on such media were, however, made.

Only on one occasion was there any evidence of reversion of these cultures to a normal staphylococcus. Cultures of three strains (two derived from PS 55 at the end of May, and one derived from Ps 42E in June, 1961), each of which had had several transfers on penicillin plates, were transferred to penicillin-free media on 22 July; subcultures to penicillin-free media were made, for one strain on $31 \mathrm{July}$ and for the other two on 18 August. All these subcultures yielded staphylococci which, though growing poorly and being coagulase-negative at first, subsequently regained a typical appearance and proved to be identical in phage type with the original parent strains of staphylococci. Further subcultures of the L-form broth cultures on penicillin-free media did not reveal staphylococci, and the above was the only occasion on which 'reversion' was observed. Since both strains of staphylococci were in use in the laboratory at the time, the appearance of staphylococci in the $\mathrm{L}$ form cultures might have been the result of coincidental contamination; but it seems more likely that the strains were at the time not yet fully stabilized in the $\mathbf{L}$ phase.

Several attempts were made later to demonstrate reversion by using $L$ forms which had been through 30 or more subcultures, 20 or more of them in penicillinfree media. These $\mathrm{L}$ cultures were plated on media in which the serum was replaced with $5 \%$ yeast extract, or in which the sodium chloride was replaced by $1.3 \%$ or $\mathbf{3 . 7} \%$ di-sodium hydrogen phosphate. No evidence of reversion to staphylococci was obtained.

\section{Characteristics of the $L$ forms}

Effect of antibiotics. The effect of antibiotics on the staphylococcal $\mathrm{L}$ forms was tested in four ways: (1) subculture of agar block cultures and of broth cultures of $\mathrm{L}$ forms to antibiotic-containing media; (2) subculture of broth cultures to L-form medium (without penicillin) and application of antibiotic-containing paper discs; (3) determination of minimal inhibitory concentration (MIC) of the antibiotics in L-form agar; (4) attempts to transform staphylococci to $\mathrm{L}$ forms on $\mathrm{L}$-form agar which contained another antibiotic in place of penicillin. The results of these tests are shown in Tables 3 and $\mathbf{4}$.

Detailed examination of the antibiotics known to interfere with cell-wall metabolism is illustrated in Table $\mathbf{3}$. The $\mathbf{L}$ forms were resistant to the inhibitory action 
of the penicillins, cephalosporin (PAC), cycloserine, vancomycin and ristocetin; but they were inhibited by novobiocin, bacitracin and crystal violet.

Table 3. Effect of antibiotics on staphylococcal $L$ forms

(The reactions in this table are mostly based on tests with $\mathrm{L}$ forms from staphylococcus ps 42E, which is sensitive to all antibiotics used.)

\begin{tabular}{|c|c|c|c|c|c|}
\hline \multicolumn{2}{|c|}{ Antibiotic ( $\mu \mathrm{g} . / \mathrm{ml})}$. & $\begin{array}{l}\text { Growth from } \\
\text { agar block } \\
\text { subculture }\end{array}$ & $\begin{array}{c}\text { Growth from } \\
\text { broth } \\
\text { subculture }\end{array}$ & $\begin{array}{l}\text { Resistance to } \\
\text { antibiotic } \\
\text { dise }\end{array}$ & $\begin{array}{l}\text { Change from } \\
\text { staphylococcus } \\
\text { to } \mathbf{L} \text { form }\end{array}$ \\
\hline Benzylpenicillin & $6-60$ & + & + & + & + \\
\hline Methicillin & $6-60$ & + & + & + & + \\
\hline Cycloserine & $200-600$ & + & + & + & + \\
\hline Cephalosporin (PAC & C) 100 & + & + & + & + \\
\hline Vancomycin & $500-1000$ & + & + & + & - \\
\hline Ristocetin & $100-1000$ & + & + & + & - \\
\hline Novobiocin & $100-1000$ & - & - & - & - \\
\hline Bacitracin & $8-20$ & - & - & - & - \\
\hline Crystal violet & 10 & - & - & - & - \\
\hline
\end{tabular}

Minimal inhibitory concentrations of several antibiotics for the $\mathbf{L}$ forms and for the parent staphylococci are shown in Table 4. For several of these antibiotics, the minimal inhibitory concentration for a staphylococcus was rather greater than that for the corresponding $\mathrm{L}$ form.

Table 4. Antibiotic sensitivity of L-forms and their parent staphylococci

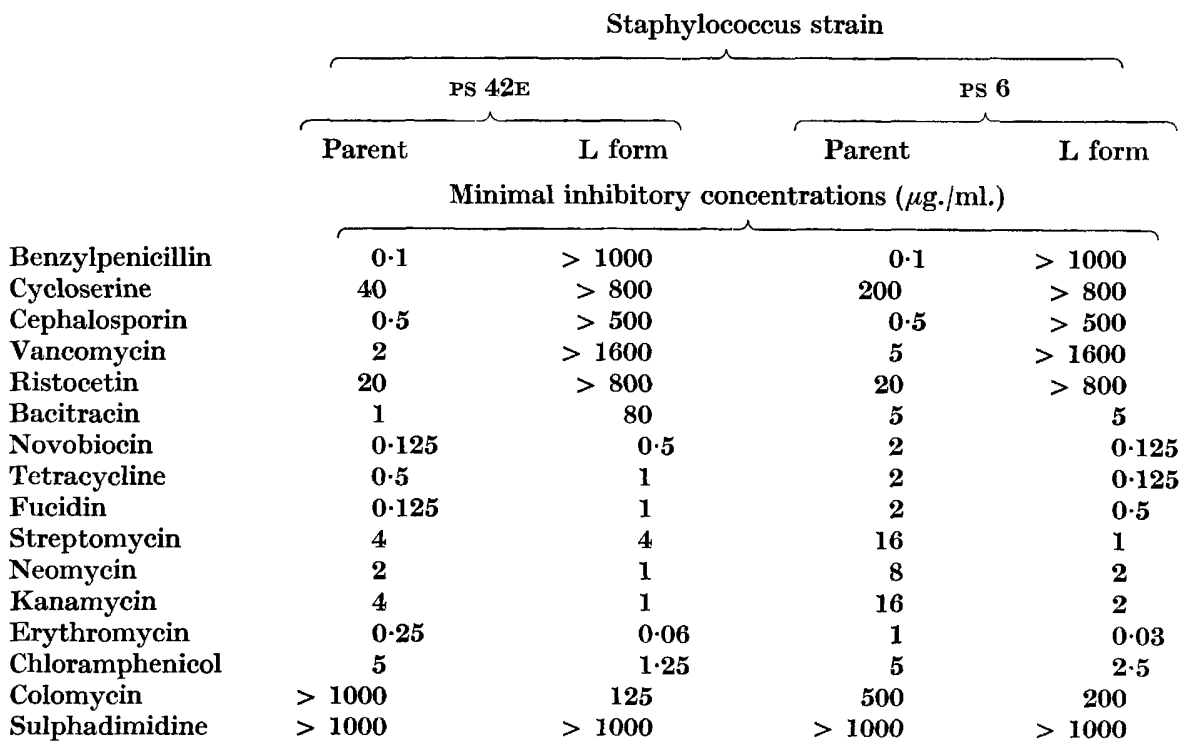

Formation of $\mathbf{L}$ forms from staphylococci was achieved with methicillin, cephalosporin and cycloserine, though the yield of $\mathrm{L}$ colonies on methicillin plates was lower than on penicillin. There was a good yield of $\mathrm{L}$ colonies on plates containing $100 \mu \mathrm{g}$. cephalosporin $/ \mathrm{ml}$. L colonies from the methicillin, cephalosporin and cycloserine plates were subcultured easily on to penicillin plates.

Several attempts were made to change staphylococci to the $\mathbf{L}$ form with vancomycin but without success. 
Phage sensitivity. Broth cultures of the L forms from staphylococci PS 42E, Ps 6 and 1444 were spread on plates of $L$-form medium without penicillin, and drops of a preparation of the polyvalent $\mathbf{K}$ phage, containing about $10^{8}$ phage particles $/ \mathrm{ml}$., were applied. There was no sign of inhibition or of lysis after overnight incubation. A similar test was made with the typing-phages active on the parent staphylococci; again there was no sign of any action.

Lysogenicity. Supernatant fluids from well-grown L-form cultures of the same three strains were spotted on to agar plates spread with cultures of staphylococci sensitive to the lysogenic phages of the parent strains. After overnight incubation the plates inoculated with the supernatant fluid of strain 1444 showed an identical lytic spectrum to that given by supernatant fluid of a broth culture of the parent staphylococcus. The L-broth culture of strains PS 6 and PS 42E did not show very convincing lysis. These tests were made with broth cultures which had been transferred in the $\mathrm{L}$ form for over a year. A further test was made with a newly isolated L-form culture from staphylococcus $42 \mathrm{E}$; the supernatant fluid of this lysed one of the staphylococci (w 57) lysed by the parent, but not strains 1030 or 18042. It was thought that this loss of lysogenicity might be explained by the selection, through resistance to phage uptake by the $\mathrm{L}$ forms, of any non-lysogenic mutants that might have occurred. An attempt was made to reproduce the effect with staphylococci grown in broth containing $1 \%$ sodium citrate to inhibit phage uptake. A streptomycin-resistant variant of staphylococcus Ps 42E was transferred 15 times in citrate broth and then spread on a nutrient agar plate at a concentration calculated to give well-spread colonies. The plate was spread with a thin layer of agar and the surface irradiated with ultraviolet radiation to kill any surviving staphylococci; after overnight incubation to allow development of colonies, a broth culture of indicator staphylococcus 1030 was spread over the surface of the agar layer, and incubation continued for a further $24 \mathrm{hr}$. Plaques of lysis were seen in the indicator lawn corresponding to most of the colonies, but about $10 \%$ of the colonies gave no plaques. These latter colonies were subcultured in streptomycin-containing broth and after further subculture were tested for lysogenicity for the indicator strain 1030; two non-lysogenic colonies were found in this way. It was of interest that both these colonies had apparently lost the prophage responsible for the lysis of strains 1030 and 18042 but retained that responsible for lysis of the third indicator strain, w 57. They thus resembled the $\mathrm{L}$ form in lytic activity.

Osmotic sensitivity. The L-form growth in a broth culture was centrifuged down and resuspended in: $(a)$ water; $(b)$ nutrient broth (containing $0.5 \% \mathrm{w} / \mathrm{v} \mathrm{NaCl}$ ); (c) L-form broth. After 15, 30 and $60 \mathrm{~min}$., samples from each were again centrifuged, resuspended in L-form broth and plated on L-form agar. The results of a typical experiment are shown in Table 5; the $\mathbf{L}$ forms were rapidly killed on suspension in water, more slowly in nutrient broth.

Several attempts were made to acclimatize the $\mathrm{L}$ forms to growth in lower concentrations of salt. It was possible to get growth in broth media containing only $1.5 \%(\mathrm{w} / \mathrm{v})$ sodium chloride, and on occasion to obtain satisfactory subculture from these cultures to agar media containing only $1.2 \%(\mathrm{w} / \mathrm{v})$ sodium chloride. The growth was never profuse but the colonies were typical in form.

Coagulase-production. Human plasma was added $(10 \%, \mathrm{v} / \mathrm{v})$ to L-form broth medium and the tubes inoculated with a broth culture of three different L-form 
cultures; characteristic clots were produced after incubation for $24-48 \mathrm{hr}$. at $37^{\circ}$; these clots were digested by a preparation containing streptokinase ("Varidase' Lederle Laboratories, N.J., U.S.A.).

Cell-wall components. A chemical analysis of $\mathrm{L}$ forms, and comparison with the parent staphylococci, is being made by my colleague Mr B. Pratt; the results will be published subsequently. In preliminary experiments it has proved impossible to detect any muramic acid in hydrolysates of three strains of $\mathrm{L}$ forms.

Table 5. Osmotic sensitivity of staphylococcal L forms

\begin{tabular}{|c|c|c|c|}
\hline & & of suspe & \\
\hline & $15 \mathrm{~min}$. & 30 min. & $60 \mathrm{~min}$. \\
\hline Susnending medium & No. & able unit & $\mathrm{ml}$ \\
\hline $\mathrm{L}$ form broth, $3.5 \% \mathrm{NaCl}$ & 3000 & 3000 & 2000 \\
\hline $0.5 \% \mathrm{NaCl}$ broth & 1700 & 400 & 250 \\
\hline Water & 70 & 15 & 15 \\
\hline
\end{tabular}

Action of lysozyme. A broth culture of the $\mathrm{L}$ form of staphylococcus PS 42E was centrifuged down, and resuspended in nutrient broth containing $\mathbf{0} \cdot \mathbf{1}$ unit egg-white lysozyme/ml.; there was no change in turbidity. After $\mathbf{3 0} \mathrm{min}$. the suspension was recentrifuged, taken up in L-form broth and plated on L-form medium. A control, exposed to the broth but not to lysozyme, yielded 150 colonies; the lysozyme-treated suspension gave 206 colonies. In a similar experiment Micrococcus lysodeikticus was sterilized by $15 \mathrm{~min}$. exposure to the lysozyme.

Filterability. A well-grown broth culture yielding about $500 \mathrm{~L}$-form colonies from $0.02 \mathrm{ml}$. was filtered through an Oxoid membrane filter, and through a series of Gradocol membranes (kindly supplied by Dr F. Himmelweit) having estimated pore sizes of 450, 300, 140 and $69 \mathrm{~m} \mu$. A few L colonies (35 from $0.02 \mathrm{ml}$.) developed from the filtrate from the Oxoid filter (pore size about $700 \mathrm{~m} \mu$.) but from none of the others. A further series of experiments were made with broth cultures of various ages passed through Oxoid membrane filters but in these the viable count of the filtrate was lower and, with cultures aged 1-4 days, never exceeded $0.5 \%$ of the original culture and was generally about $0 \cdot 1 \%$. Membrane filters were also laid on the surface of L-form medium agar and inoculated with drops of staphylococcus culture and of an L-form broth culture. The staphylococcus and its $\mathrm{L}$ form grew on the surface of the filter, though less well than on the agar surface. After incubation for several days on the surface of the agar, the staphylococci and the $L$ forms grew through the membrane to the underlying agar; but there was no indication that the $\mathrm{L}$ forms did so more readily than did the staphylococci.

Lyophilization. The L-form cultures have been successfully preserved by lyophilization, the centrifuged deposit from a broth culture being suspended in normal horse serum and freeze-dried in an Edwards Centrifugal Freeze Dryer. 


\section{DISCUSSION}

It has thus been possible to obtain colonies which resemble those described for $\mathrm{L}$ forms from most of the staphylococci tested. Since the numbers of L-form colonies obtained in repeated experiments with single staphylococcal strains were very variable, it seems likely that the few failures were due to technical difficulties rather than to a real inability of some staphylococcal strains to be changed. This confirms the observations of Schönfeld (1961), as do the observations on the early stages of L-colony formation. Schönfeld did not, however, record the formation of large numbers of abortive L-form colonies. No explanation has been found for the irregularity of the appearance of $\mathrm{L}$-form colonies. The observation that many abortive L-form colonies develop indicates that there are at least two stages at which lack of some factor required for growth or the presence of some growthinhibitory factor might act. Schönfeld (1961) found that the number of L-form colonies was related to the square of the number of staphylococci in the inoculum; it was for this reason that a standard inoculum of a 10-times concentrated culture was used in the present work. In my hands the irregularity from one plate to another has been too great to permit useful statistical analysis in this respect. A similar irregularity has so far prevented proper attempts to discover whether the $\mathrm{L}$ forms may occur as mutants in normal cultures of staphylococci and merely be selected by penicillin + high $\mathrm{NaCl}$ concentrations. Our inability to obtain L-form colonies by exposing staphylococci to vancomycin or ristocetin, which are not inhibitory to growing L-form cultures, is perhaps some evidence against the mutational origin; likewise an observation that the yield of $\mathbf{L}$-form colonies from staphylococci grown in L-form broth and plated on L-form agar is no higher than from staphylococci grown in nutrient broth, in which any $\mathbf{L}$ forms would have been destroyed.

The antibiotic sensitivity of the $\mathbf{L}$ forms conforms reasonably to expectation based on other information about the mode of action of various compounds on cell wall synthesis (e.g. Salton, 1960; Reynolds, 1961). It is interesting that the growth of the $\mathbf{L}$ forms is inhibited by bacitracin, which has recently been shown to inhibit staphylococcal growth in more ways than simply by interference with cell-wall synthesis (Smith \& Weinburg, 1962); perhaps novobiocin can also be shown to have multiple effects. The apparently greater susceptibility of $L$ forms than the parent organisms to several antibiotics is presumably due to greater ease of penetration in the absence of cell wall, and conforms well with Taubeneck's (1962) observations on $\mathbf{L}$ forms of Proteus.

Apart from the comparative sensitivity to various antibiotics, the conclusion that the staphylococcal $\mathbf{L}$ forms described here lack cell walls is supported by their insusceptibility to phage and their osmotic sensitivity. Reversion to staphylococci has not been convincingly observed so that, formally, there might be some doubt whether the colonies were truly derived from staphylococci. Their continuing coagulase production and, at least to a limited extent, their lysogenicity, as well as the fact that they have been isolated on many separate occasions from several different staphylococcal strains seems, however, to counter this objection. It seems that the partial loss of lysogenicity is due to the selection, by prolonged culture in the phage-resistant $\mathbf{L}$ form, of non-lysogenic mutants.

The stability of our penicillin-induced $L$ forms of staphylococci is of interest in 
view of the apparent regularity with which Schönfeld (1959) and Marston (1961 a) were able to demonstrate reversibility of the $L$ phase in their cultures. Perhaps the strains investigated in the present work differed from the strains of Schönfeld and Marston, especially in having been stabilized for a longer period in the $\mathbf{L}$ form; more probably we have not yet achieved the right growth conditions for reversion.

I wish to thank Miss S. Harding and Miss J. Corse for their technical assistance during this work. I am also grateful to Messrs Eli Lilly and Co. for supplies of cycloserine, to Leo Laboratories Ltd. for fucidin, and to Glaxo Research Ltd. for cephalosporin.

\section{REFERENCES}

Blair, J. E. \& Williams, R. E. O. (1961). Phage typing of staphylococci. Bull. World Hlth. Org. 24, 771.

Dienes, L. \& Sharp, J. (1956). The role of high electrolyte concentration in the production and growth of $\mathrm{L}$ forms of bacteria. J. Bact. 71, 208.

Gooder, H. \& MAXTED, W. R. (1961). External factors influencing structure and activities of Streptococcus pyogenes. Symp. Soc. gen. Microbiol. 11, 151.

Marston, J. (1961a). Observations on L forms of staphylococci. J. infect. Dis. 108, 75.

Marston, J. (1961b). Cultivation of staphylococcal L forms in a liquid medium. J. Bact. $81,832$.

Mattman, L. H., Tunstall, L. H. \& Rossmoone, H. W. (1961). Induction and characteristics of staphylococcal L forms. Canad. J. Microbiol. 7, 705.

Prozorovskir, S. V. (1959). Production by pathogenic staphylococci of stabilized cultures of L forms and their biological properties. J. Microbiol. Epidem. Immunobiol. 30, 117.

REynolds, P. E. (1961). Studies on the mode of action of vancomycin. Biochim. biophys. Acta, 52, 403.

Salton, M. R. J. (1960). Microbial Cell Walls. New York: J. Wiley and Sons 1960.

SchöNFELd, J. K. (1959). 'L' Forms of staphylococci; their reversibility; changes in the sensitivity pattern after several intermediary passages in the ' $L$ ' phase. Antonie van Leeurwenhoek J. Microbiol. Serol. 25, 325.

Schönfeld, J. K. (1961). 'L' Forms of Staphylococcus. II. Studies on the morphology of the transformation and on the reversibility. Antonie van Leeurenhoek J. Microbiol. Serol. 27, 139.

Smith, J. L. \& Weinburg, E. D. (1962). Mechanisms of antibacterial action of Bacitracin. J.gen. Microbiol. 28, 559.

TAUbeneck, U. (1962). Susceptibility of Proteus mirabilis and its stable L forms to erythromycin and other macrolides. Nature, Lond. 196, 195. 